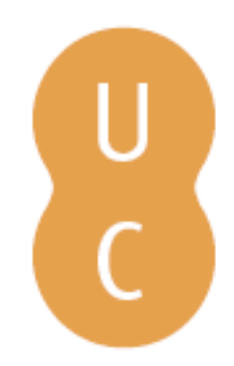

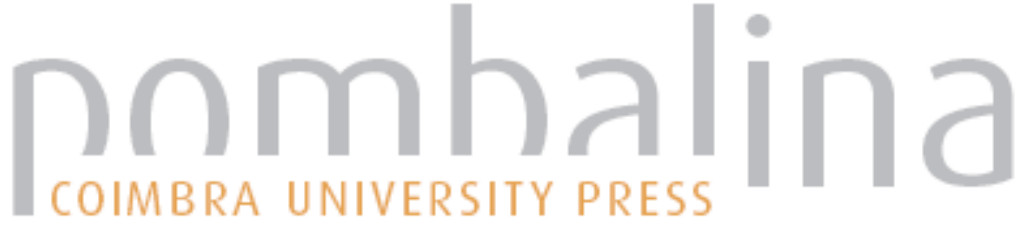

\section{Estimativa da idade por métodos dentários}

Autor(es): $\quad$ Cunha, Eugénia; Wasterlain, Sofia

Publicado por: Imprensa da Universidade de Coimbra

URL

persistente: URI:http://hdl.handle.net/10316.2/38418

DOI: $\quad$ DOI:http://dx.doi.org/10.14195/978-989-26-0963-8_5

Accessed : $\quad$ 26-Apr-2023 10:26:49

A navegação consulta e descarregamento dos títulos inseridos nas Bibliotecas Digitais UC Digitalis, UC Pombalina e UC Impactum, pressupõem a aceitação plena e sem reservas dos Termos e Condições de Uso destas Bibliotecas Digitais, disponíveis em https://digitalis.uc.pt/pt-pt/termos.

Conforme exposto nos referidos Termos e Condições de Uso, o descarregamento de títulos de acesso restrito requer uma licença válida de autorização devendo o utilizador aceder ao(s) documento(s) a partir de um endereço de IP da instituição detentora da supramencionada licença.

Ao utilizador é apenas permitido o descarregamento para uso pessoal, pelo que o emprego do(s) título(s) descarregado(s) para outro fim, designadamente comercial, carece de autorização do respetivo autor ou editor da obra.

Na medida em que todas as obras da UC Digitalis se encontram protegidas pelo Código do Direito de Autor e Direitos Conexos e demais legislação aplicável, toda a cópia, parcial ou total, deste documento, nos casos em que é legalmente admitida, deverá conter ou fazer-se acompanhar por este aviso.

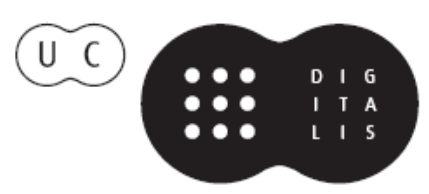




\section{IDENTIFICAÇÃO EM MEDICINA DENTÁRIA FORENSE}

ANA CORTE-REAL DUARTE NUNO VIEIRA COORDENAÇÃO 
Capítulo V

Estimativa da idade por métodos dentários

Estimativa da idade em indivíduos não adultos

Cronologia de erupção

Desenvolvimento dentário

Métodos dentários de estimativa da idade

em indivíduos adultos

\section{Eugénia Cunha \\ Sofia Wasterlain}




\section{RESUMO:}

Apresentam-se os principais métodos dentários usados na estimativa da idade de indivíduos não adultos e adultos da prática forense. Os métodos com base na análise radiológica podem ser aplicados tanto em cadáveres como em indivíduos vivos. Os exames radiográficos panorâmicos, ortopantomografias, são mandatórios e os resultados destes costumam ser cruzados com indicadores esqueléticos, designadamente a ossificação dos ossos da mão e do punho. O interesse do tema motivou a criação de grupos interdisciplinares, como por exemplo, o AGFAD (grupo de estudo alemão), tendo elaborado, no ano 2000, as primeiras normas europeias para a estimativa da idade de indivíduos vivos sujeitos a procedimentos criminais. Destacam-se as metodologias empregues em não adultos que são bastante mais assertivas que as usadas em indivíduos adultos, o que se fica a dever à maior disponibilidade de indicadores etários e regularidade dos mesmos, em detrimento de processos fisiológicos dependentes de fatores externos. Consequentemente, o desvio padrão associado obrigatoriamente a cada estimativa etária é tanto maior, quanto mais velho for o indivíduo. Se num bebé podemos ter um desvio padrão de 18 meses, na adolescência esse intervalo aumenta para 2-4 anos e num adulto há métodos que podem chegar a valores de 16 anos. Este aumento do desvio padrão com o avançar da idade é uma prova da maior falibilidade dos métodos existentes para estimar a idade dos adultos.

\section{PALAVRAS-CHAVE:}

estimativa da idade, erupção dentária, desenvolvimento dentário.

\section{ABSTRACT:}

This chapter presents the main methods used in forensic practice for dental age estimation of non-adults and adults. The methods based on radiological analysis can be applied in living individuals and in cadavers. The panoramic radiographs are mandatory and these results are often crossed with skeletal indicators, namely the ossification of the bones of the hand and wrist. The interest in the subject led to the creation of interdisciplinary groups, such as AGFAD (German study group), having in 2000 established the first European norms for age estimation of living individuals liable to criminal prosecution. We highlight the methodologies employed in non-adults which are much more assertive than those used in adults, due to the greater availability and reliability of age indicators, instead of physiological processes that dependent on external factors. Consequently the standard deviation necessarily associated with each age estimate is higher in older the individuals. If a baby can have a standard deviation of 18 months, during adolescence this range increases for 2-4 years and an adult there are methods that can reach values of 16 years. This increase in the standard deviation as the age advances is a testimony of the unpredictability of the methods for age estimation in adults.

\section{KEYWORDS:}

age estimation, tooth eruption, tooth development. 


\section{V.1 INTRODUÇÃO}

Os dentes são autênticas "caixas negras» dos indivíduos, particularmente úteis na estimativa da idade e na data da morte. Neste capítulo serão abordados os principais métodos dentários usados na estimativa da idade, considerando dois grupos de indivíduos, não adultos e adultos. No âmbito da antropologia forense este parâmetro está inserido dentro dos fatores genéricos de identificação, correspondentes ao perfil biológico, que pode posteriormente ser comparado com o dos indivíduos constantes nas listagens de desaparecidos. No âmbito da Medicina Dentária Forense, pode auxiliar na resolução de processos civis ou judiciais, em que se pretende estimar a idade de indivíduos indocumentados e a sua identificação, em situações de adoção, imputabilidade e pedopornografia [1].

Para melhor entendimento deste capítulo serão esclarecidos os conceitos de idade cronológica versus idade biológica. Enquanto a primeira se refere ao número real de anos/ meses vividos, ou seja, à idade que consta no documento de identificação, a segunda é a idade que se aparenta ter e que pode ser estimada através dos ossos, designada por idade óssea, ou com base nos dentes, designada por idade dentária. A correlação entre a idade cronológica e a idade dentária não é a ideal, ou seja, a correlação não é exatamente igual a $1(r=1)$, mas a idade dentária tem vantagem sobre a óssea ao conseguir uma melhor e mais fiel aproximação [2]. Destaca-se que o valor obtido de estimativa da idade é mais próximo da idade cronológica nos individuos não adultos comparativamente aos indivíduos adultos. Isto acontece basicamente porque o crescimento é bastante melhor conhecido que o envelhecimento. Durante o crescimento há, efetivamente, uma série de alterações quase regulares que estão muito bem correlacionadas com a idade. Inversamente, quanto mais velho for um indivíduo, menos indicadores etários existem e, sobretudo, por estes serem multifatoriais e, implicitamente, mais variáveis, a correlação da idade estimada e a idade cronológica está longe de ser a ideal.

A relevância do tema, no âmbito da Medicina Dentária, reporta ao sec. XIX. Neste período de tempo, a implementação do trabalho fabril, nomeadamente em Inglaterra, estabelecia que uma criança com idade inferior a 7 anos era inimputável e o mesmo não sucedia para idades superiores, em que eram punidos pela lei no seu incumprimento [3]. A referência médico-legal para estimar a idade, segundo Thomson, era a presença ou não do primeiro molar na cavidade oral [4]. Ainda neste século, a distribição do horário de trabalho era efetuada em função da idade, sendo que, o horário de trabalho num indivíduo acima dos 18 anos tinha início às $5 \mathrm{~h} 30 \mathrm{~m}$ e terminava às $20 \mathrm{~h} 30 \mathrm{~m}$; indivíduos com idades compreendidas entre 13 e 18 anos não podiam trabalhar por um período superior a $12 \mathrm{~h}$, tendo um intervalo de 1,5 h para a refeição; para crianças com idades compreendidas entre 9 e 13 anos, não era permitido trabalhar mais de 9 horas e crianças com idade inferior a 9 anos eram proibidas de trabalhar [5]. Pelo exposto, o estudo da estimativa de idade surge num contexto multidisciplinar, social, económico, legal e médico. 


\section{V.2. ESTIMATIVA DA IDADE EM INDIVÍDUOS NÃO ADULTOS}

O grupo de «não adultos» pode ser subdividido segundo quatro faixas etárias: fetos (cuja idade é estimada em semanas de vida intrauterina); recém-nascidos, também designada por primeira infância (entre 0 e os 6 anos); segunda infância (entre os 7 e os 12 anos) e adolescência (dos 12 aos 18 anos). 0 desenvolvimento embrionário do dente, tem início com o desenvolvimento fetal, sendo que o grau de mineralização do esmalte é uma carateristica morfológica de análise numa radiografia. Para o grupo dos fetos a estimativa da idade dentária é efetuada pela presença e pelo estadio de formação da porção coronária dos dentes decíduos. Destaca-se que um dos critérios de feto de termo é a presença do achado radiográfico da mineralização das pontas da cúspide do primeiro molar decíduo. Na primeira e segunda infância a cronologia de erupção e o desenvolvimento dentário, envolvendo a transição entre as duas dentições, decídua e definitiva, são características relevantes na estimativa da idade. No grupo dos adolescentes, destaca-se o estudo dos dentes definitivos pré-molares e terceiros molares, nomeadamente a formação radicular e a rizogénese dentária, analisadas pela morfologia do tecido dentário radicular.

O profundo conhecimento da calcificação/ mineralização e respetiva erupção de cada um dos 20 dentes decíduos e de cada um dos 32 dentes definitivos coloca a cronologia e o desenvolvimento da dentição como indicadores ímpares na avaliação da idade de indivíduos não adultos.

Atualmente, os dentes são tidos como o meIhor indicador individual da idade cronológica das crianças e jovens. O desenvolvimento dentário, comparativamente com o desenvolvimento ósseo e de caracteres genitais, é menos afetado por fatores ambientais e hormonais. A cronologia de erupção é tida como um indicador relevante na estimativa da idade, neste grupo de estudo, por ser um processo de curta duração, permitindo intervalos de desvio padrão mais curtos e uma estimativa mais precisa, comparativamente ao desenvolvimento dentário completo, que é um processo longo e contínuo [6-11].

Podemos considerar que a idade dentária pode ser estimada segundo o tipo de metodologia: por esquemas/atlas, em que a dentadura em causa é situada num estadio cronológico, pela avaliação e aplicação de estadios de mineralização para um dente ou grupo de dentes e por métodos biométricos, incorporadas numa função discriminante. Para um melhor entendimento deste capítulo será efetuado uma subdivisão dos métodos segundo o objeto em estudo: a cronologia, o desenvolvimento dentário e as alterações fisiológicas.

\section{V.2.1. CRONOLOGIA DE ERUPÇÃO}

Durante, aproximadamente, os primeiros 20 anos de vida os dentes estão em formação podendo se estabelecer várias etapas, bem definidas de desenvolvimento, ou seja, erupção e mineralização dentárias. A formação dos dentes começa por volta das 14-16 semanas depois da conceção [12] (fig. V.1). Pode considerar-se, posteriormente, quatro grandes momentos: o primeiro refere-se à emergência de todos os dentes decíduos, o que acontece entre, aproximadamente, os 6 meses e os 2-2,5 anos; entre os 6 e os 8 anos, erupcionam, 


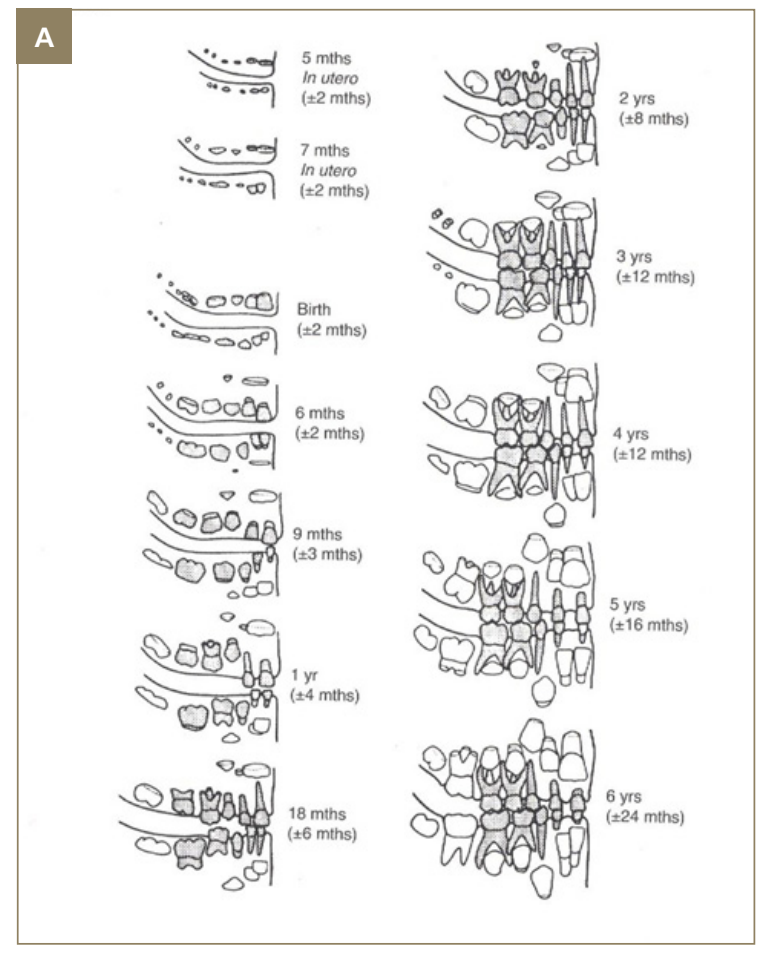

B

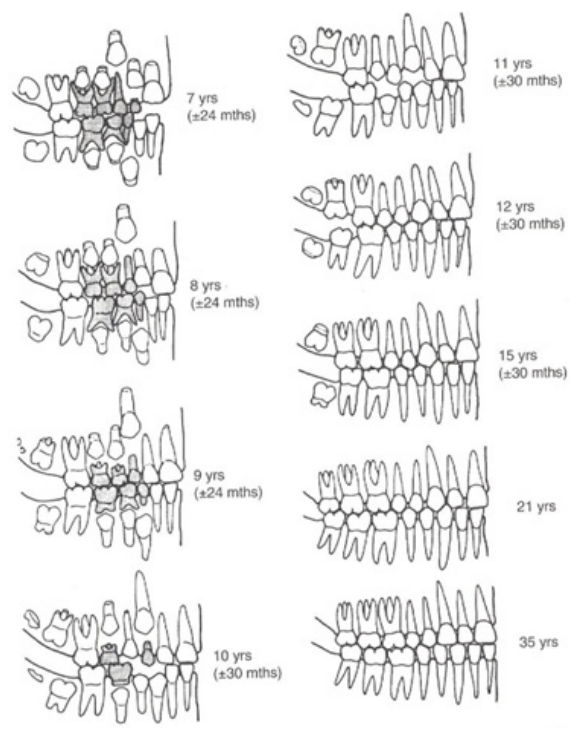

Figura V.1. (A e B) - Reprodução dos esquemas de Ubelaker de 1989 (Autorização de autor). os incisivos e os primeiros molares, permanentes; entre os 10 e os 12 anos, erupcionam os pré-molares e os segundos molares definitivos; por último os terceiros molares servem como indicadores etários.

Os métodos do estudo da cronologia de erupção compreendem a colocação do indivíduo num estadio prédeterminado de um esquema/ atlas a que corresponde um intervalo de idades. A inserção do individuo pode não corresponder a um desenho prédefinido mas sim a um estadio intermédio pelo que se deve considerar as idades de ambos os estadios limite.

Em 1978, Ubelaker, elaborou um diagrama da cronologia de erupção dentária, posteriormente editado, concomitantemente, como um esquema de desenvolvimento dentário tendo por base de dados a dentição definitiva de uma população nativa americana [13] (fig. V.1).

No que se refere à estimativa da idade, este diagrama não apresenta a variabilidade sexual, como considera o canino (dente com marcado dimorfismo sexual), um dente a evitar, sempre que possível.

\section{Método do Atlas de Londres}

O mais recente atlas de cronologia de erupção e desenvolvimento dentário é o «The London Atlas of human tooth development and eruption", publicado por AlQahtani e colaboradores, em 2010 [14]. Este trabalho foi obtido a partir de 176 restos esqueletizados da coleção do museu de história natural de Londres, Reino Unido e do Real Colégio de cirurgiões de Inglaterra, bem como, de 578 radiografias de indivíduos vivos. São no total 31 imagens, a partir das 30 semanas 


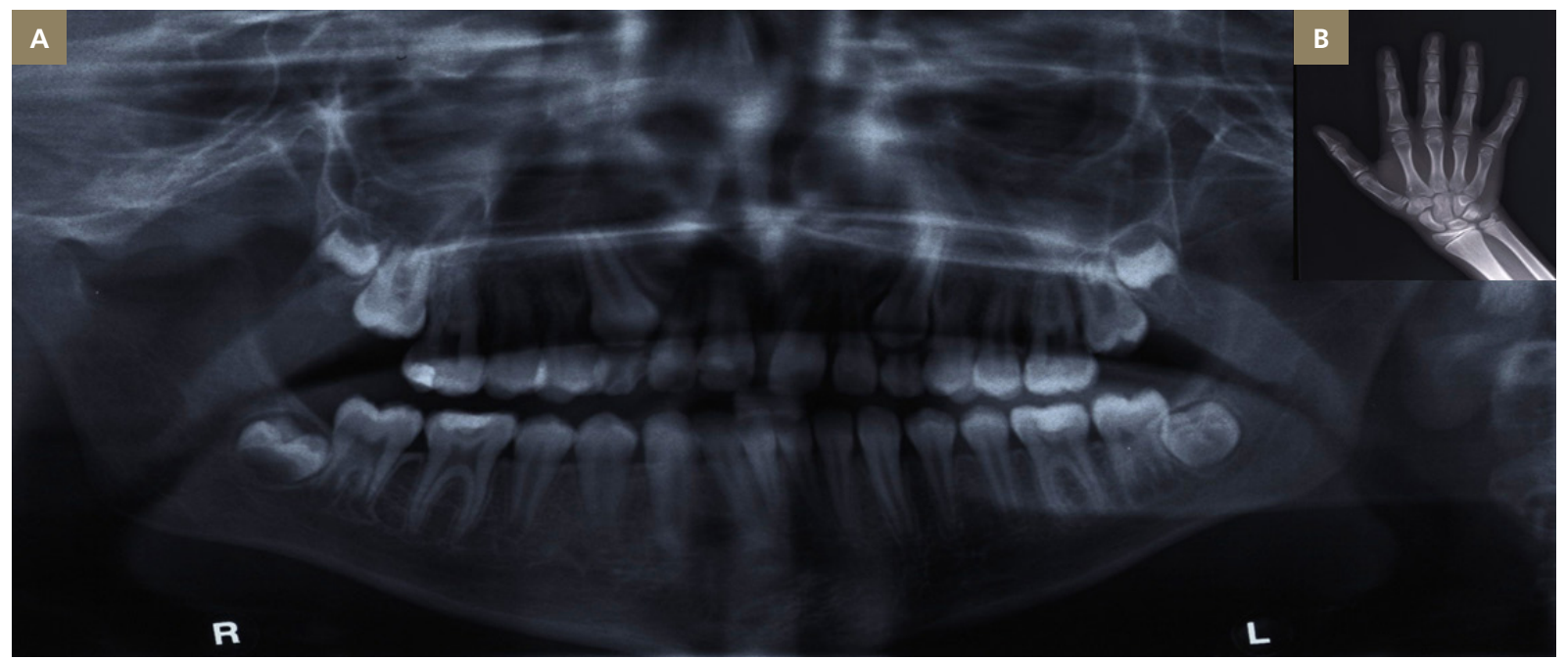

Figuras V.2 (A e B) - Exames radiográficos para estimar idade cronológica. (A) Ortopantomografia. (B) Radiografia da mão e punho do lado não dominante de um indivíduo com 12 anos de idade.

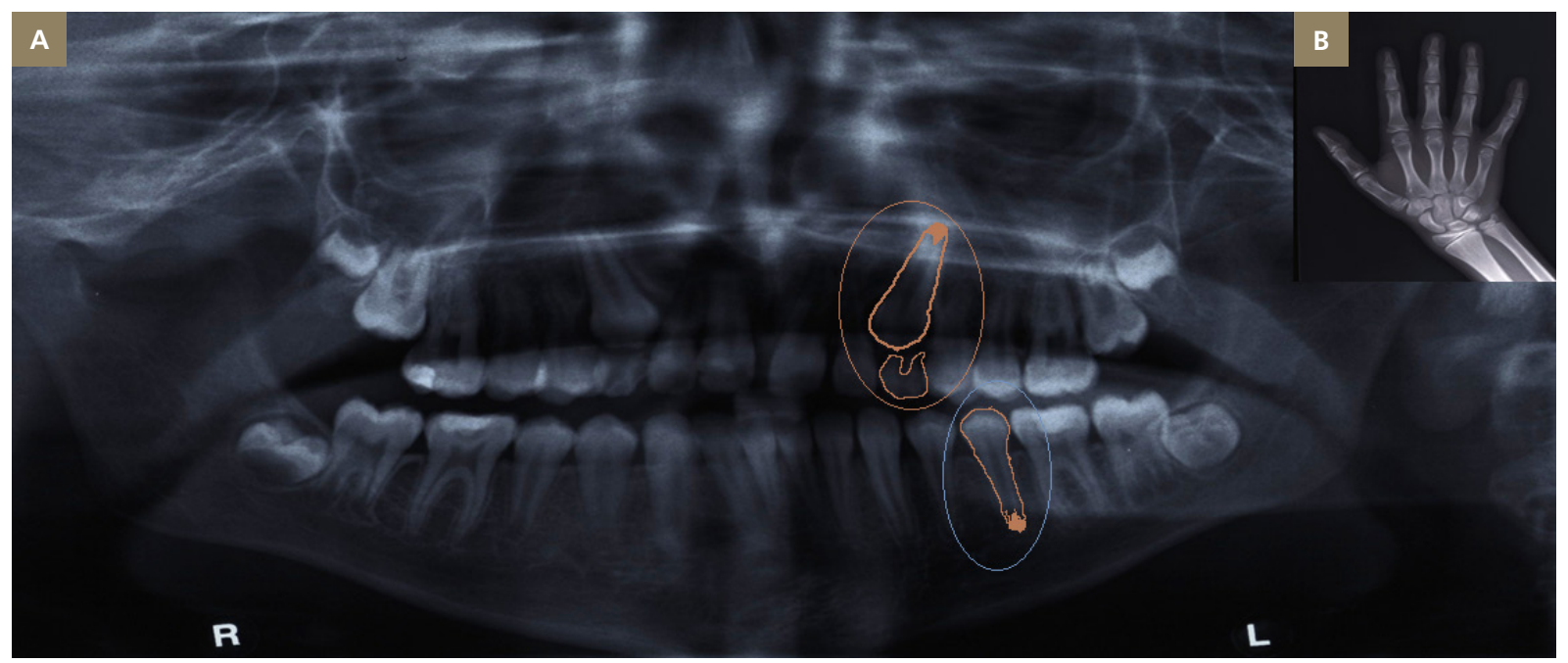

Figuras V.3 (A e B) - Exames radiográficos para estimar idade cronológica. (A) Análise da ortopantomografia pelo método de comparação de diagrama do Atlas de Londres. (B) Radiografia da mão e punho do lado não dominante. Atribuição do estadio correspondente a 11.5 anos face à imagem de 23; atribuição do estadio de 13.5 anos face à imagem de 35. Estimativa de idade entre 11.5 e 13.5 anos. 
intrauterinas até aos 23.5 anos de idade; oito das imagens descrevem o desenvolvimento do terceiro molar desde 16.5 anos; não está indicado um desvio padrão para cada imagem. Destaca-se que enquanto nas imagens do diagrama de Ubelaker a etapa de erupção do dente tem como referência o local de emergência do dente a nível gengival, no Atlas de Londres a referência é o rebordo ósseo (figs. V.2 e V.3).

Salienta-se que a metodologia por diagrama (atlas ou esquemas) apresenta os seguintes problemas: não considera a variação do género; não existem estudos para populações específicas e existe uma grande variabilidade entre distintos observadores.

\section{2.2. DESENVOLVIMENTO DENTÁRIO}

Considera-se o incremento dos métodos com base em técnicas não invasivas como relevante no estudo da idade. Os registos radiográficos de rotina permitem obter a informação necessária para aplicar diversos diagramas, conforme será adiante abordado $[2,16]$.

Tabela V.1 - Dados cronológicos do desenvolvimento dos dentes humanos [15].

\begin{tabular}{|c|c|c|c|c|c|c|c|}
\hline Dentes Decíduos & $\begin{array}{l}\text { Incisivo } \\
\text { Central }\end{array}$ & $\begin{array}{l}\text { Incisivo } \\
\text { Lateral }\end{array}$ & Canino & $\begin{array}{l}\text { Primeiro } \\
\text { Molar }\end{array}$ & $\begin{array}{l}\text { Segundo } \\
\text { Molar }\end{array}$ & & \\
\hline \multicolumn{8}{|c|}{ Maxilar } \\
\hline $\begin{array}{l}\text { Inicial mineralização } \\
\text { Formação completa da coroa } \\
\text { Formação completa da raiz }\end{array}$ & $\begin{array}{l}14 \mathrm{~s} \\
1.5 \mathrm{~m} \\
1.5 \mathrm{a} \\
\end{array}$ & $\begin{array}{c}16 \mathrm{~s} \\
2.5 \mathrm{~m} \\
2 \mathrm{a} \\
\end{array}$ & $\begin{array}{c}17 \mathrm{~s} \\
9 \mathrm{~m} \\
3.25 \mathrm{a} \\
\end{array}$ & $\begin{array}{l}15.5 \mathrm{~s} \\
6 \mathrm{~m} \\
2.5 \mathrm{a} \\
\end{array}$ & $\begin{array}{c}19 \mathrm{~s} \\
11 \mathrm{~m} \\
3 \mathrm{a}\end{array}$ & & \\
\hline \multicolumn{8}{|c|}{ Mandibular } \\
\hline $\begin{array}{l}\text { Inicial mineralização } \\
\text { Formação completa da coroa } \\
\text { Formação completa da raiz }\end{array}$ & $\begin{array}{l}14 \mathrm{~s} \\
1.5 \mathrm{~m} \\
1.5 \mathrm{a}\end{array}$ & $\begin{array}{l}16 \mathrm{~s} \\
2 \mathrm{~m} \\
1.5 \mathrm{a}\end{array}$ & $\begin{array}{c}17 \mathrm{~s} \\
9 \mathrm{~m} \\
3.25 \mathrm{a}\end{array}$ & $\begin{array}{l}15.5 \mathrm{~s} \\
5.5 \mathrm{~m} \\
2.5 \mathrm{a}\end{array}$ & $\begin{array}{c}18 \mathrm{~s} \\
10 \mathrm{~m} \\
3 \mathrm{a}\end{array}$ & & \\
\hline Dentes Definitivos & $\begin{array}{l}\text { Incisivo } \\
\text { Central }\end{array}$ & $\begin{array}{l}\text { Incisivo } \\
\text { Lateral }\end{array}$ & Canino & $\begin{array}{l}\text { Primeiro } \\
\text { PréMolar }\end{array}$ & $\begin{array}{l}\text { Sgundo } \\
\text { PréMolar }\end{array}$ & $\begin{array}{c}\text { Primeiro } \\
\text { Molar }\end{array}$ & $\begin{array}{c}\text { Segundo } \\
\text { Molar }\end{array}$ \\
\hline \multicolumn{8}{|c|}{ Maxilar } \\
\hline $\begin{array}{l}\text { Inicial mineralização } \\
\text { Formação completa da coroa } \\
\text { Formação completa da raiz }\end{array}$ & $\begin{array}{c}3-4 \mathrm{~m} \\
3-4 \mathrm{a} \\
10 \mathrm{a}\end{array}$ & $\begin{array}{c}10-12 \mathrm{~m} \\
4-5 \mathrm{a} \\
11 \mathrm{a}\end{array}$ & $\begin{array}{c}4-5 \mathrm{~m} \\
6-7 \mathrm{a} \\
13-15 \mathrm{a}\end{array}$ & $\begin{array}{c}1.5-1.75 a \\
5-6 a \\
12-13 a\end{array}$ & $\begin{array}{l}2-2.25 \text { a } \\
6-7 a \\
12-14 a\end{array}$ & $\begin{array}{c}\text { Ao } \\
\text { nascer } \\
2.5-3 \text { a } \\
9-10 \text { a }\end{array}$ & $\begin{array}{c}2.5 \mathrm{a} \\
7-8 \mathrm{a} \\
14-16 \mathrm{a}\end{array}$ \\
\hline \multicolumn{8}{|c|}{ Mandibular } \\
\hline $\begin{array}{l}\text { Inicial mineralização } \\
\text { Formação completa da coroa } \\
\text { Formação completa da raiz }\end{array}$ & $\begin{array}{c}3-4 m \\
4-5 a \\
9 a\end{array}$ & $\begin{array}{c}3-4 m \\
4-5 a \\
10 a\end{array}$ & $\begin{array}{c}4-5 \mathrm{~m} \\
6-7 \mathrm{a} \\
12-14 \mathrm{a}\end{array}$ & $\begin{array}{c}1.5-2 \mathrm{a} \\
5-6 \mathrm{a} \\
12-13 \mathrm{a}\end{array}$ & $\begin{array}{c}2.25-2.5 \mathrm{a} \\
6-7 \mathrm{a} \\
13-14 \mathrm{a}\end{array}$ & $\begin{array}{c}\text { Ao } \\
\text { nascer } \\
2.5-3 \text { a } \\
9-10 \text { a }\end{array}$ & $\begin{array}{c}2.5-3 a \\
7-8 a \\
14-16 a\end{array}$ \\
\hline
\end{tabular}

Fonte: Esquema adaptado In Manual of Forensic Odontology 5th Ed. David R Senn Richard Weems 2013.

Legenda: s (semanas intrauterinas); $m$ (mês); a (anos) 
Estes diversos estudos têm por base a análise individual de cada dente e variam no número de imagens ou estadios considerados. Tendo em conta que o período de desenvolvimento dentário completo é um processo longo, na estimativa da idade são consideradas as seguintes metas: formação da coroa, início da formação da porção radicular ou a bifurcação canalar; rizogénese completa; emergência na cavidade oral e início da esfoliação nos dentes decíduos. A cada imagem corresponde uma descrição morfológica dos tecidos dentários, considerando distintos indicadores na formação da coroa e da raíz. Estas características são avaliadas separadamente para cada dente e por arcada dentária (figs. V.3). Segundo Anderson, considera-se que os primeiros molares são os dentes de eleição na estimativa de idade não dependente do género, de acordo com o mesmo estudo, os terceiros molares são os mais dependentes [17].

\section{Método de Demirjian}

Os trabalhos de Demirjian e seus colaboradores $[2,18]$ têm relevante aplicação na estimativa da idade e são considerados ainda hoje como método de eleição. Os autores consideram 8 estadios de calcificação, designados de $\mathrm{A}$ a $\mathrm{H}$ para um dente, desde o início da calcificação da coroa (estádio $\mathrm{A}$ ), até ao encerramento da raiz pela formação completa do apex (estadio H) (tab. V.2). Posteriormente, os estadios são convertidos em valores quantitativos, ou scores, conforme o género, através duma tabela específica para determinado grupo populacional. Esta técnica deve ser aplicada aos 7 dentes de uma hemiarcada inferior (excluindo o terceiro molar), pela melhor qualidade radiográfica deste setor numa ortopantomografia. Os valores das pontuações dos sete dentes são somados, para obter um score de maturidade dentária, ou seja, um valor entre

Tabela V.2 - Descrição dos estadios de Demirjian $[2,18]$.

\begin{tabular}{|c|c|c|c|}
\hline Estadio & Descrição & Estadio & \begin{tabular}{c} 
Descrição \\
\hline A
\end{tabular} \\
$\begin{array}{c}\text { Definição do gérmen dentário. Inicío } \\
\text { da formação da anatomia coronária } \\
\text { com o deliniar do cume das cúspides. }\end{array}$ & E & $\begin{array}{c}\text { Início da formação da bifurcação } \\
\text { radicular. A altura radicular é menor } \\
\text { do que a altura coronária. }\end{array}$ \\
\hline B & $\begin{array}{c}\text { Coalescência das cúspides e } \\
\text { definição da morfologia oclusal. }\end{array}$ & F & $\begin{array}{c}\text { A altura radicular é idêntica } \\
\text { à altura coronária. }\end{array}$ \\
\hline C & $\begin{array}{c}\text { Formação de metade da coroa, } \\
\text { esmalte e dentina, iniciando a } \\
\text { morfologia da cavidade pulpar }\end{array}$ & G & $\begin{array}{c}\text { Paredes radiculares paralelas, } \\
\text { formação radicular incompleta }\end{array}$ \\
\hline D & $\begin{array}{c}\text { Formação completa dos tecidos } \\
\text { mineralizados da coroa até à junção } \\
\text { cemento-dentinária. Início da definição } \\
\text { morfológica da camara pulpar. }\end{array}$ & H & Formação completa do dente \\
com rizogénese completa.
\end{tabular}




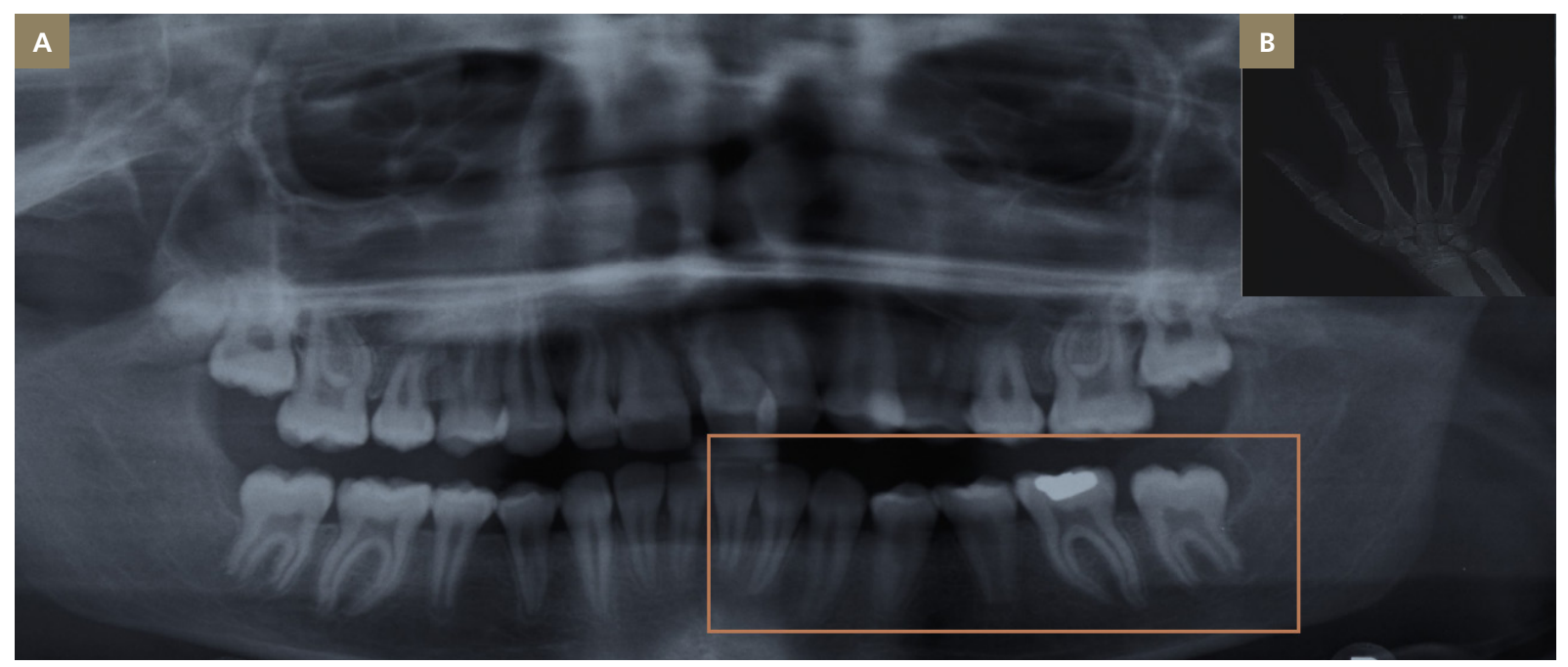

Figuras V.4 (A e B) - Exames radiográficos para estimar idade cronológica. (A) Ortopantomografia. (B) Radiografia da mão e punho do lado não dominante de um indivíduo estimada pela análise dos sete dentes mandibulares segundo Demirjian.

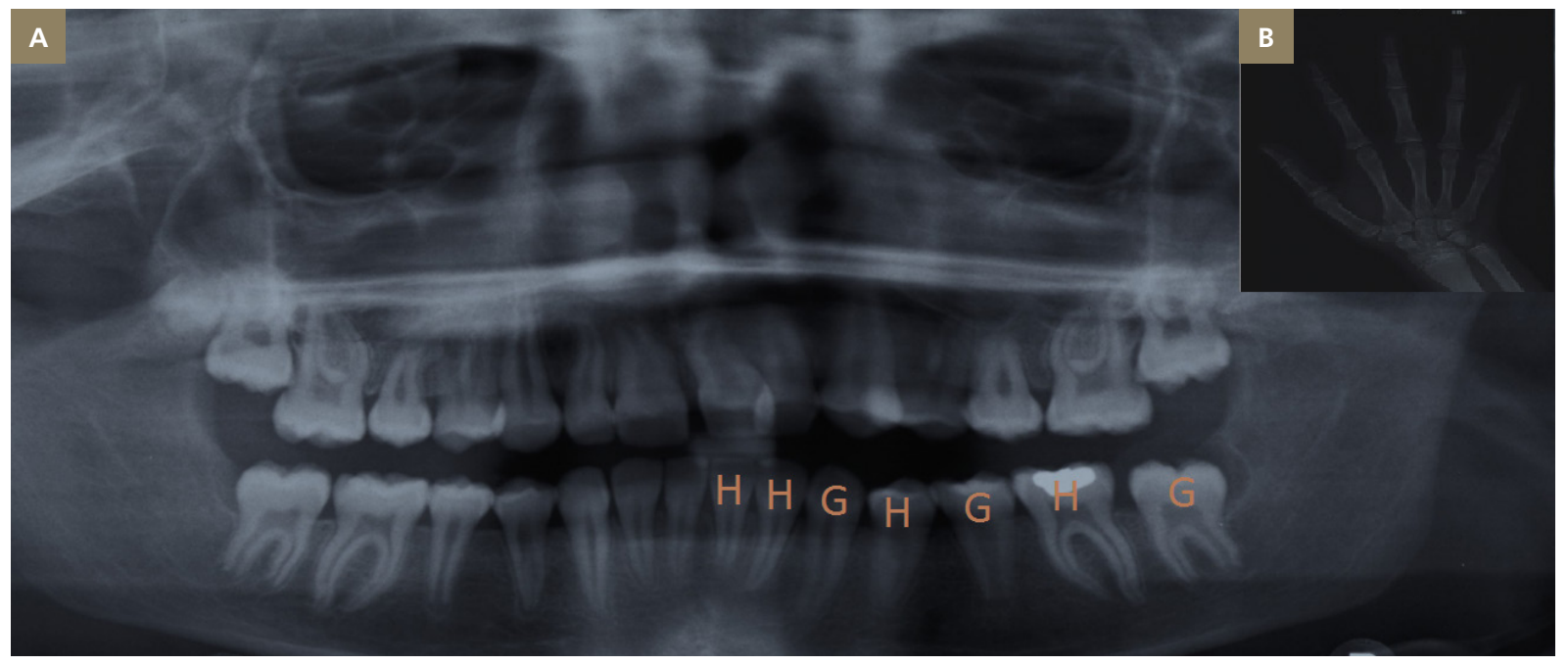

Figuras V.5 (A e B) - Exames radiográficos para estimar idade cronológica. (A) Análise da ortopantomografia pelo método de análise dos dentes do $3^{\circ}$ quadrante, segundo Demirjian. (B) Radiografia da mão e punho do lado não dominante. Atribuição do estadio correspondente H-31; H-32; G-33; H-34; G-35; H-36; G-37. Estimativa de 14 anos de idade. 


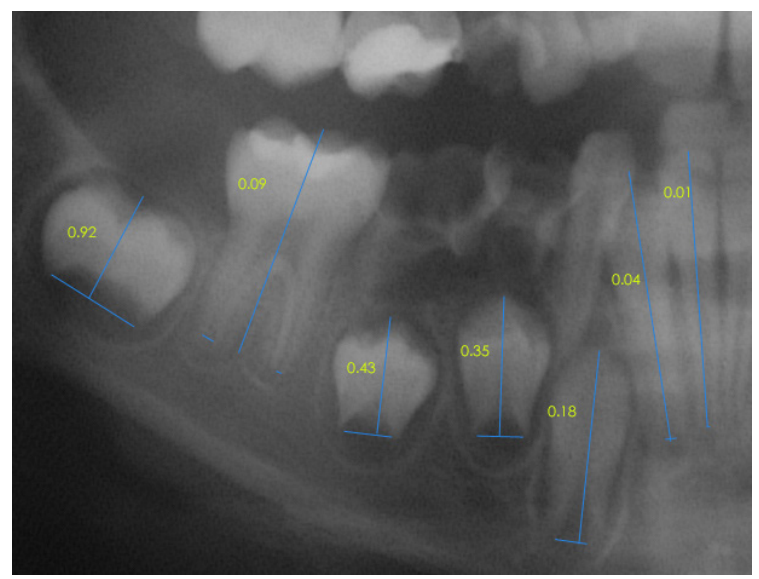

Figura V.6 - Ortopantomografia de um individuo com dentição mista, aplicação do método de Cameriere.

0 e 100, que é posteriormente convertido numa idade dentária através de uma tabela de conversão própria para a referida população. O método original baseia-se numa amostragem significativa de ortopantomografias de 1446 rapazes e 1482 raparigas franco-canadianas. Em 1976, este método foi simplificado passando a usar-se apenas quatro dentes, dois pré-molares e dois molares [17]. Este método tem vindo a ser aplicado a outras populações, dos quais enumeram-se os seguintes: belga [19], alemã [20] e australiana [21].

\section{Método de Cameriere}

Cameriere e colaboradores propuseram, em 2006, um método de estimativa da idade na presença de dentes em desenvolvimento, através da mensuração da abertura apical, durante o processo de apexicificação. A amostragem deste método consiste em 455 crianças caucasianas italianas. Os autores obtiveram uma equação de regressão para o segundo pré-molar. Para efetuar as medições é utilizado o software Photoshop CS $5{ }^{\circledR}$ Adobe ${ }^{\circledR}$ e para minimizar a distorção, na fórmula, a mensuração da abertura do ápex é dividida pela altura total do dente (fig. V.6) [22]. Este método foi posteriormente testado em amostras independentes que revelaram níveis bastante aceitáveis de precisão [23]. Ainda assim, em 2007, a equipa de Cameriere tentou melhorar e expandir a investigação com um maior número de crianças ( $\mathrm{N}=2652$ ) provenientes de vários países Europeus e fornecer uma fórmula comum que pudesse ser utilizada em todos esses países [24].

\section{Método de Mincer}

No final da adolescência, apenas o desenvolvimento do terceiro molar pode ser estudado e fornece informação sobre a idade fisiológica. Entre os métodos desenvolvidos, enumera-se o Método de Mincer [25], para a atribuição da "meta" dos 18 anos a partir da presença ou não dos quatro dentes terceiros molares erupcionados na cavidade oral. O estudo deste autor teve por base uma amostragem significativa ( $\mathrm{N}=823)$, concluindo que cerca de $90 \%$ dos adolescentes com os terceiros molares erupcionados, tinham efetivamente idade superior a 18 anos. É de assinalar que os terceiros molares maxilares são mais precoces na erupção do que os mandibulares [26]. A ausência congénita frequente, o mal posicionamento na arcada e as malformações, são alguns dos fatores que fazem dos dentes 18, 28, 38 e 48 demasiadamente falíveis. De referir ainda que a origem 

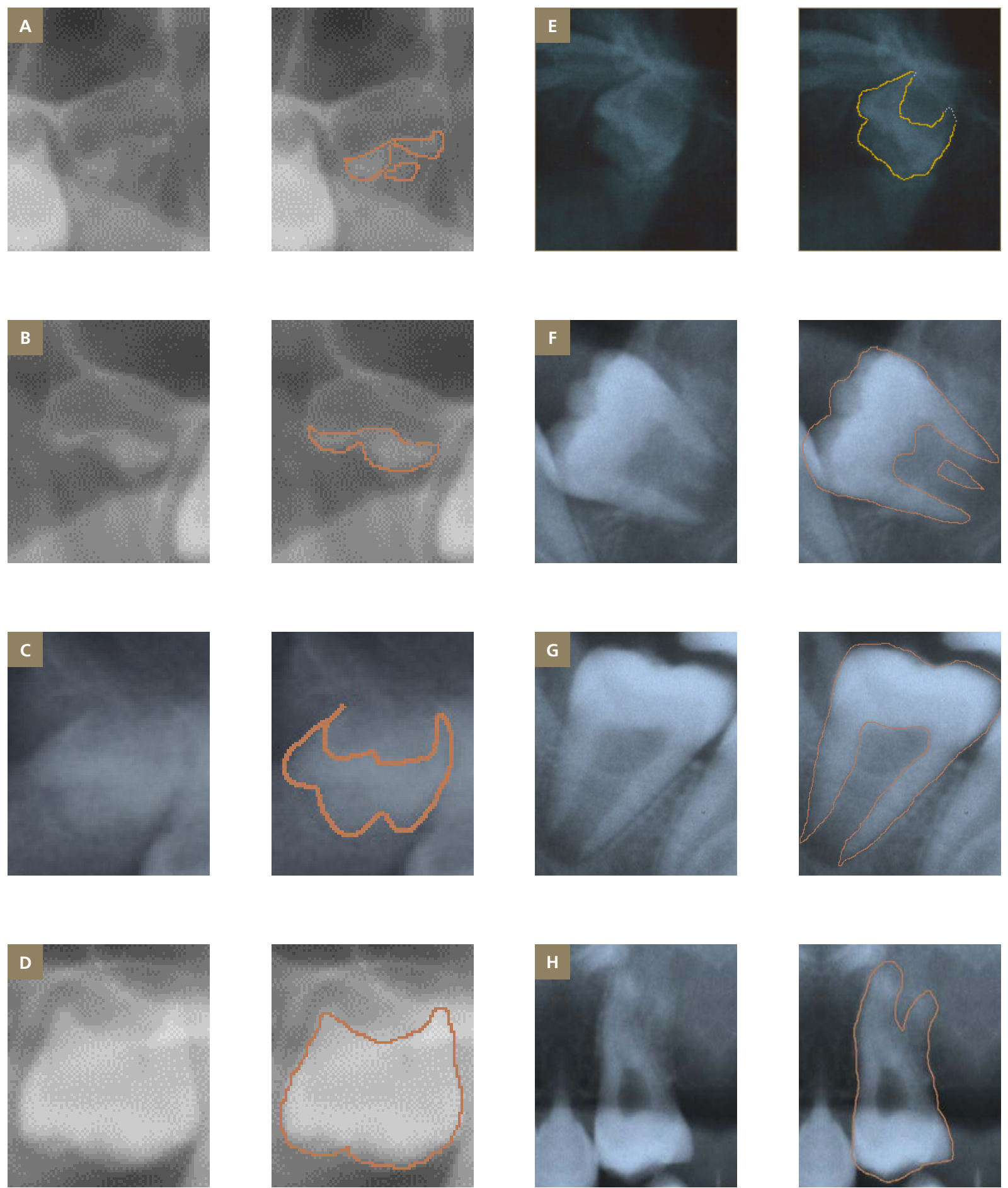

Figuras V.7 (A,B,C,D,F,G e H) - Análise dos estadios de desenvolvimento dentário do terceiro molar segundo o diagrama de desenvolvimento morfológico de Demirjian e Goldstein [18]. 
geográfica influencia a maturação destes dentes e Liversidge [27] comprovou que num grupo de adolescentes negros sul-africanos a maturação destes dentes é mais precoce.

Face ao facto dos quatro terceiros molares não se encontrarem, frequentemente e em simultâneo, num mesmo indivíduo, crê-se que estes dentes não deverão ser utilizados isoladamente como indicadores etários.

O primeiro teste ao método de Ubelaker [13] numa amostra portuguesa foi efetuado em 1999, com 64 esqueletos não adultos (entre os 7 e os 21 anos) da Coleção de Esqueletos Identificados da Universidade de Coimbra. O diagrama de Ubelaker mostrou ser um critério assertivo [8]. Em 2005, Delgado Tomás, numa amostra populacional portuguesa, de 270 crianças portuguesas de ambos os géneros, com idades compreendidas entre os 6 e os 14 anos, verificou ser possível a aplicabilidade dos métodos de Nolla [29] e de Demirjian e seus colaboradores [7]. Dois anos mais tarde, Paula Júlio [30] realiza a sua dissertação sobre a estimativa da idade em indivíduos vivos não adultos, numa amostragem de 512 indivíduos portugueses, 261 raparigas e 251 rapazes, com idades entre os 6 e os 16 anos, aplicando o método de Demirjian e Goldstein [18]. Esta autora conclui que, por este método, a idade das raparigas está sobrestimada em 0,41 anos, a dos rapazes em 1,57 anos, o que implica que o método de Demirjian necessita de algumas adaptações à população portuguesa.

Merecem igualmente referência os trabalhos de Cardoso sobre a demonstração duma consistente aceleração na maturação dentária radicular devida a mudanças seculares numa amostra de 521 individuos, rapazes e raparigas, portugueses [31]. O mesmo autor reforçou, para a população portuguesa, numa amostra de esqueletos portugueses imaturos $(n=41)$, que o desenvolvimento dentário é menos afetado por fatores ambientais do que a maturação esquelética. Este autor estudou ainda as equações de regressão de Liversidge e Molleson [32] que estimam a idade com base no comprimento dos dentes permanentes numa amostra esquelética juvenil identificada, tendo concluído pela aplicabilidade do método [33]. O mesmo teste foi efetuado para a dentição decídua [34], onde o autor ressalta as vantagens do método métrico em detrimento dos métodos baseados em estadios de desenvolvimento.

A erupção dos terceiros molares na população portuguesa é bem conhecida devido aos trabalhos de Caldas e colaboradores $[35,36]$. Os autores concluíram que é possível estimar a idade com base na emergência alveolar, gengival e completa. A emergência completa revelou-se um critério credível.

\section{V.3. MÉTODOS DENTÁRIOS DE ESTIMATIVA DA IDADE EM INDIVÍDUOS ADULTOS}

Uma vez que todos os dentes presentes na boca tenham alcançado a sua total formação, ou seja, a rizogénese, o desenvolvimento dentário deixa de ser critério útil na estimativa da idade. As técnicas para estimar a idade em indivíduos adultos têm por base indicadores dentários associados a alterações fisiológicas. A priori, quanto mais jovem for um indivíduo, maior será a volumetria da cavidade pulpar; inversamente, quanto mais idoso, menor será esta volumetria, face à deposição de dentina secundária e terciária. Destaca-se que com a idade ocorre formação de 

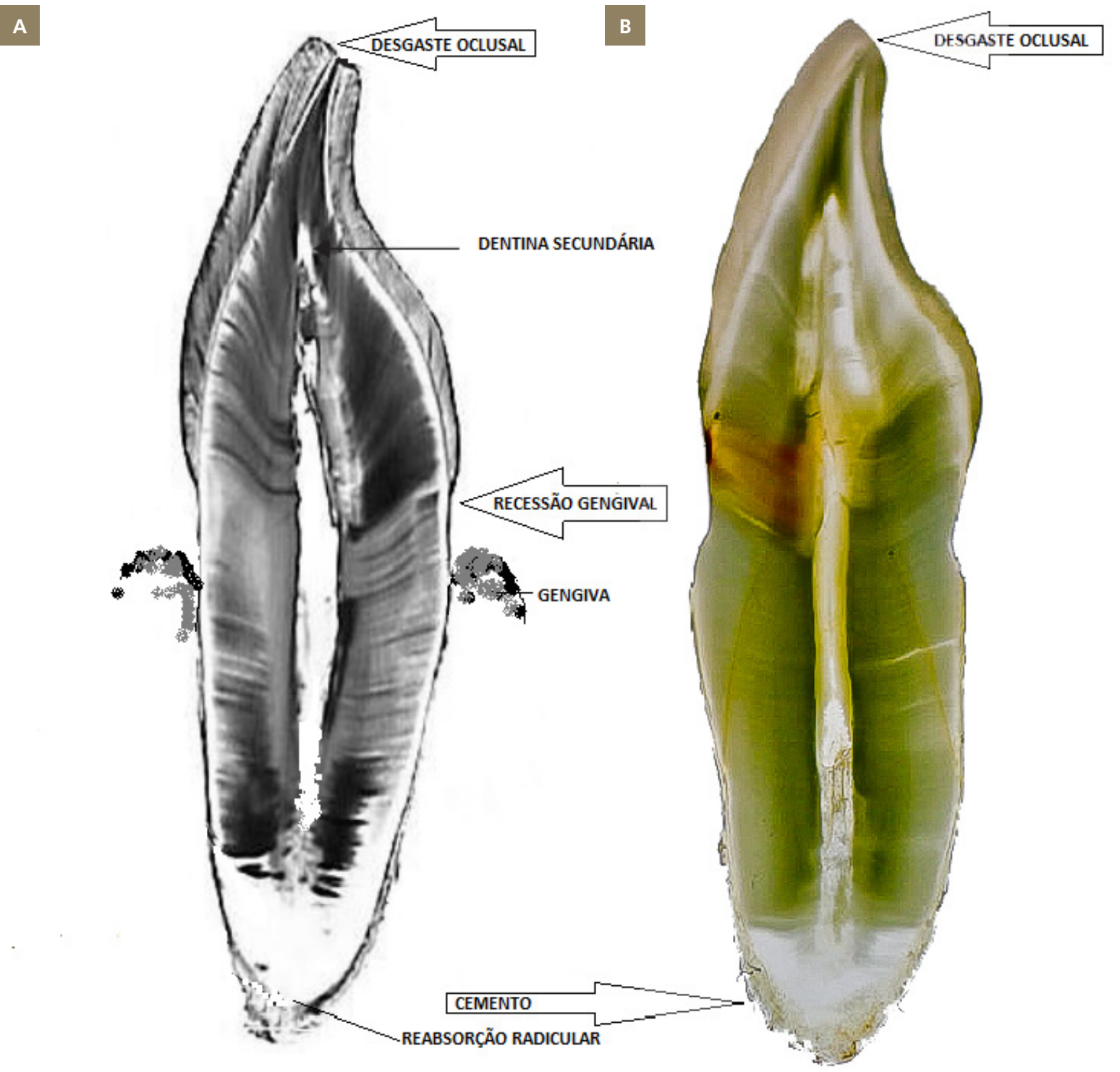

Figuras V.8 (A e B) - Incisivo central inferior de indivíduo adulto, corte longitudinal de $2 \mathrm{~mm}$ de espessura (A) Esquema de dente. (B) Imagem fotográfica.

cemento e aumento da translucidez radicular pela formação de dentina esclerótica. As técnicas de Kvall e Solheim [37] estão particularmente adequadas a situações arqueológicas.
Em termos genéricos, realça-se ainda o escurecimento dos dentes com a idade, que se tornam mais amarelos e cinzentos. Várias razões estão subjacentes a este fenómeno, nomeadamente a 
redução da espessura do esmalte, a degradação do material orgânico da dentina e a aposição de material exógeno [38, 39].

\section{Método de Gustafson}

Gustafson pode ser considerado como um dos grandes pioneiros nos métodos de estimativa da idade de indivíduos adultos: conjugou vários indicadores etários para dentes unirradiculares, designadamente: o desgaste oclusal, a deposição de dentina secundária, a recessão gengival, a aposição de cemento radicular e a reabsorção e transparência radicular apical (fig. V.8). Cada parâmetro é quantificado através de uma escala que varia de 0 a 3 , de acordo com o diagrama criado por este autor. O somatório dos pontos de cada dente é depois inserido numa equação de regressão que fornece a idade [40].

Os vários parâmetros de Gustafson foram estudados isoladamente e em associação. Miles [3] considerou que entre os parâmetros de Gustafson, o desgaste oclusal era o mais fidedigno e calibrou a severidade do desgaste em função do padrão de erupção dos molares com sucesso. O desgaste diferencial dos molares em jovens adultos, pressupõe que o último dos molares a erupcionar apresente as cúspides quase intactas, concomitantemente o $1^{\circ}$ molar, com cerca de 12 anos de mastigação, poderá apresentar um desgaste do vértice cuspídeo correspondente à exposição de dentina a olho nu. Outros autores tentaram quantificar este parâmetro pela aplicação de escalas, como é exemplo, a escala de Molnar [41]. A etiologia multifatorial do desgaste oclusal é uma realidade pelo que deve considerar-se no estudo deste parâmetro a dieta do indivíduo e a análise da oclusão, sendo um indicador que não pode ser utilizado isoladamente.

Realça-se a alteração a este método efetuada por Johanson, que recomenda a análise da oclusão, número e localização dos dentes presentes e potenciais hábitos para o estudo de todos os dentes unirradiculares presentes. Este autor sugere ainda a análise dos dentes após a sua secção em cortes de cerca de $2,5 \mathrm{~mm}$ incluindo a cavidade pulpar. A utilização de vários dentes pressupõe a obtenção de um valor médio de cada parâmetro e a aplicação da fórmula de regressão, com coeficiente de relação específico para cada um deles, porém sem considerar o género. Segundo a fórmula de regressão de Johanson pode obter-se um desvio padrão aproximado de 10 anos considerando o estudo de vários dentes e de cerca de 16 anos quando considerando apenas um dente [42].

Quanto ao método de Gustafson, outras alterações surgiram, nomeadamente por Maples, em 1978 [43]. Este autor considerou apenas os parâmetros de deposição de dentina secundária e de translucidez radicular e associou um coeficiente de correlação com a posição do dente na respetiva arcada.

\section{Método de Cameriere}

O estudo da deposição de dentina secundária e terciária está na base do método de Cameriere. Este autor desenvolveu um método aplicado à análise do canino em radiografias (figs. V.9). A escolha deste dente tem por base ser o dente mais duradouro, potencialente menos suscetível a desgaste e por ter a maior 

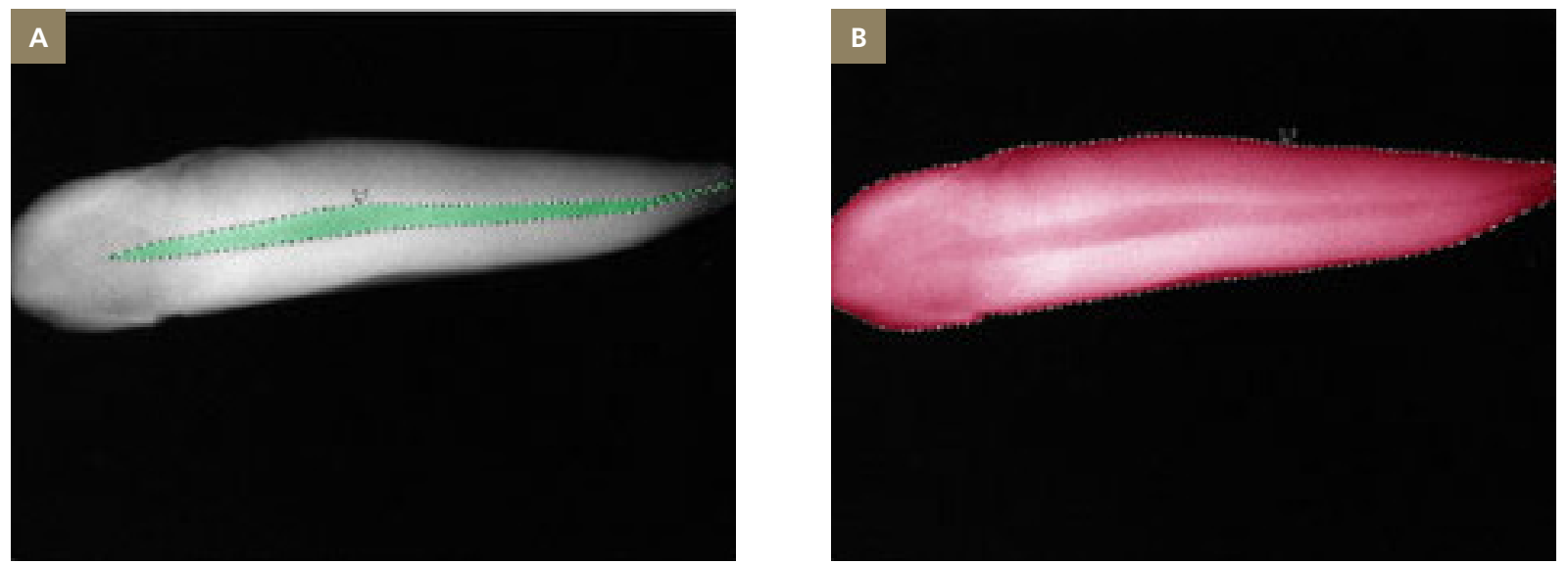

Figuras V.9 (A e B) - Registos radiográficos de dentes adultos, analisados pelo método de Cameriere.

cavidade pulpar. O método foi testado em várias amostras populacionais, como em Itália, México, Bósnia, Espanha, Brasil e também Portugal [24]. Foi provada a utilidade do método no âmbito forense, quer para indivíduos vivos como em restos humanos [46]. Foi provada a utilidade do método no âmbito forense, quer para indivíduos vivos como em restos cadavéricos. No caso português, a metodologia foi testada numa amostra de 126 caninos masculinos e 132 femininos dos indivíduos da Coleção de Esqueletos Identificados da Universidade de Coimbra, aos quais foram efetuadas radiografias periapicais. Foram obtidas equações de regressão para os caninos superiores e inferiores que explicam 97\% da variância total. Ultimamente esta técnica tem sido aplicada a outros dentes unirradiculares [47].

\section{Método de Kvaal}

Um outro método não invasivo, desenvolvido por Kvaal e colaboradores [37], tem por base a análise dos tipos de dentina, secundária e terciária, em dentes monorradiculares e em radiografias periapicais. Este método quantifica indiretamente a deposição de dentina através da mensuração da altura e largura do dente e da respetiva cavidade pulpar, ou seja, avalia as reduções progressivas do tamanho da cavidade pulpar pela deposição destes dois tipos de dentina. O dente em estudo não deve estar em má oclusão, nem ter carga excessiva ou restaurações ou cáries ativas, bem como não devem ser observados sinais de erosão, abrasão e atrição. A mensuração mesiodistal da cavidade pulpar é efetuada em três níveis e para minimizar a distorsão e a angulação da execução 


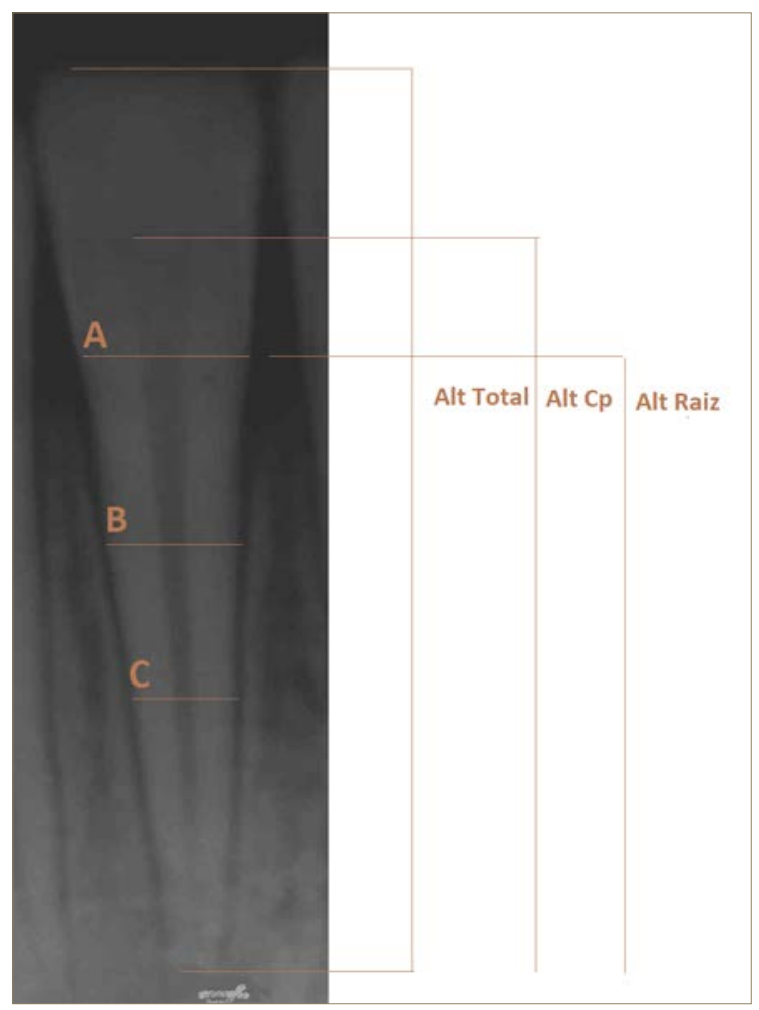

Figura V.10 - Imagem radiográfica periapical do 31. Assinaladas as mensurações segunda Kvaal: verticais e horizontais.

técnica da radiografia são consideradas mensurações verticais (fig. V.10). Kvaal considera a correlação com a posição do dente e a respetiva arcada e a separação de género quando estuda o incisivo lateral inferior. Este autor considera ainda de eleição o estudo de todos os tipos de dentes, dos dois quadrantes oponentes para estimar a idade do indivíduo.

O método tem sido razoavelmente assertivo para as populações europeias, mas apresentou faIhas quando aplicado a populações indianas [48].

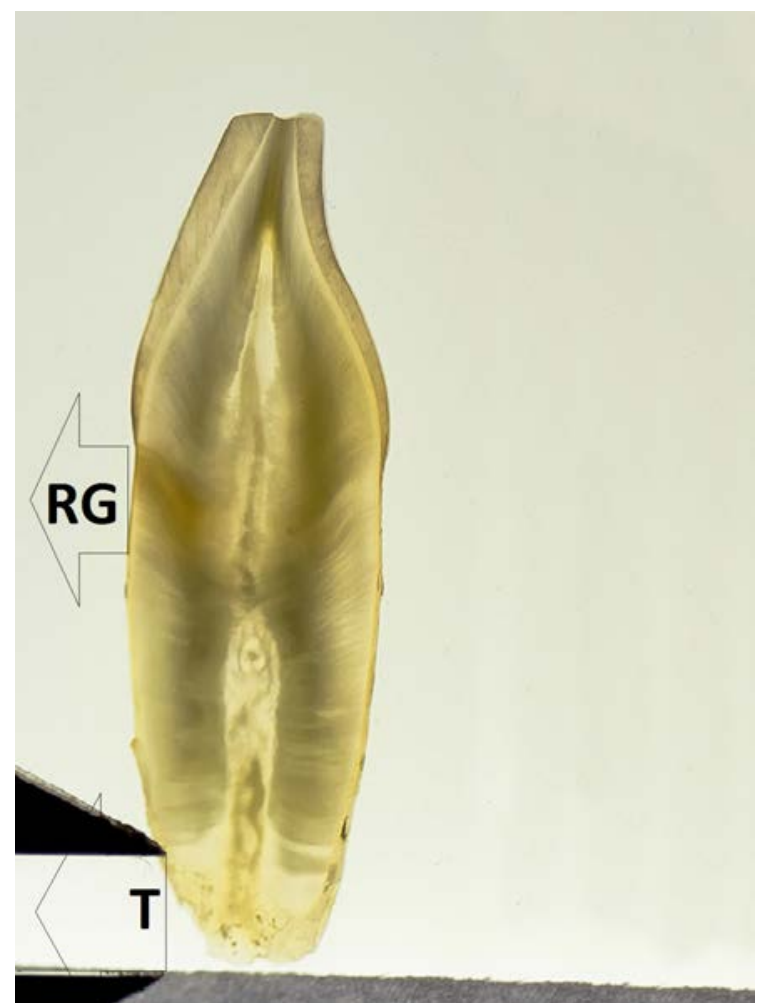

Figura V.11 - Observação, sob fonte de luz, da seção longitudinal de um incisivo central de indivíduo adulto, com cerca de 55 anos de idade. Mensuração da transparência radicular ( $\mathrm{T}$ ) com calibrador digital e assinalado a recessão gengival (RG).

\section{Método de Lamendin}

O estudo da transparência radicular está relacionado com a formação fisiológica de uma dentina esclerótica na porção apical do dente, ou seja, a hipermineralização da dentina radicular apical (fig. V.11). No âmbito da estimativa da idade, vários autores estudaram este parâmetro com destaque para os trabalhos do norueguês Solheim [49] e Bang e Ramm [50], técnicas que podem ser aplicadas a dentes intactos e secionados. 


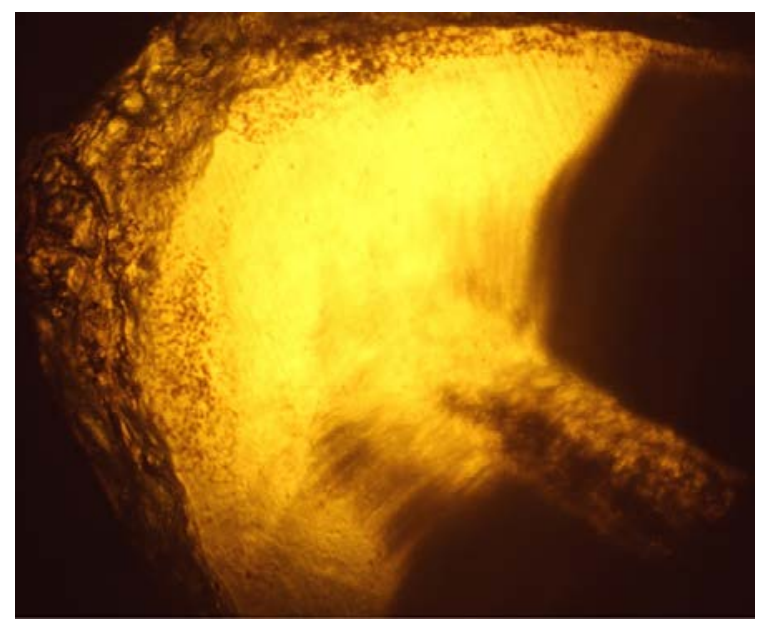

Figura V.12 - Observação ampliada $(10 \times 10)$ da porção apical de um dente, com destaque para a passagem da fonte de luz.

Bang e Ramm [50] reduziram a sua técnica de estimar a idade ao parâmetro da translucidez radicular. A mensuração é efetuada longitudinalmente, a nível do contorno vestibular e lingual do dente e obtida a média em milímetros (fig. V.11 e V.12) [50]. Todas estas metodologias têm sido objeto de revisão em termos de validade e fiabilidade [51].

Lamendin, em 1992, estudou o parâmetro de translucidez radicular associado à recessão gengival [52]. Este dentista francês propôs uma equação de regressão a partir de mensurações em milímetros (por craveira digital) da translucidez, recessão gengival e comprimento da raiz [53]. Os resultados obtidos têm demonstrado uma grande assertividade na estimativa da idade de adultos entre 25-30 anos e com 70 anos. Para cada década existe um desvio padrão que em média é de cerca de 10 anos. É uma técnica aplicada a dois tipos de dentes, incisivo e canino, com maior fiabilidade para o incisivo central superior. As medidas são realizadas na superfície vestibular dos dentes, previamente extraídos e mantidos à temperatura ambiente (fig. V.12).

É o tipo de método que se pode considerar fácil de utilizar, na medida em que não é dispendioso e não requer técnicas muito específicas. Os vários testes que têm sido efetuados em diversas amostras populacionais mostram que é recomendado desenvolver padrões específicos para cada população. Uma investigação que testou oito métodos de estimativa da idade [51] e uma outra que avaliou a performance comparativa de três indicadores esqueléticos e da técnica de Lamendin [54] demonstraram que a técnica de Lamendin tem uma alta fiabilidade e é facilmente reproduzível. Uma contraindicação do método, que só deve ser aplicado em casos forenses, é que falha quando a doença periodontal é muito avançada, o que pode querer dizer que não é assertivo nem recomendado para indivíduos muito idosos.

Este método foi combinado com um indicador esquelético, designadamente a metamorfose das sínfises púbicas [método de Suchey-Brooks (SB)] e ficou conhecido por método TSP, Two Steps Procedure que preconiza o diagnóstico sexual com base na bacia. Se se obtiver as fases I, II ou III do método, os intervalos etários correspondentes são validados e podem ser corroborados pela extremidade esternal da clavícula. Se, no entanto, o método SB cair nas fases IV, V ou $\mathrm{VI}$, porque os intervalos etários correspondentes 
são demasiadamente amplos, deve recorrer-se à técnica de Lamendin [53].

\section{A perda de dentes ante mortem}

A perda de dentes ante mortem está longe de poder ser um critério credível já que a sua etiologia é marcadamente polifatorial não estando linearmente relacionada com o avançar da idade. Já quando todos os dentes são perdidos em vida o processo de reabsorção alveolar vai provocar alterações significativas no maxilar e na mandíbula. Os foramina mentalia, que se encontram equidistantes dos bordos superior $\mathrm{e}$ inferior da mandíbula vão-se aproximando gradualmente do rebordo superior com o avançar do processo de reabsorção. Em consequência, o ângulo mandibular vai aumentando podendo chegar a $185^{\circ} \mathrm{em}$ indivíduos idosos. Mais uma vez é um método falível, que só deve ser usado como mero indicador. A nossa prática forense tem demonstrado que não é um critério suficiente para diferenciar indivíduos de 70 e 90 anos de idade.

\section{Cronologia do cemento}

Este método tem vindo a adquirir uma importância crescente na antropologia forense. Baseia-se na contagem das linhas do cemento da raiz dentária. Como o cemento é formado dum modo contínuo ao longo da vida, não sofrendo processos de remodelação, permite uma estimativa da idade bastante credível. É conhecido por TCA - Tooth Cementum Annulation - e tem dado bons resultados para dentes que estiveram em contacto com o fogo [55].

\section{Técnicas bioquímicas}

As proteínas são elementos estruturais do nosso organismo, constituídas por aminoácidos. Os aminoácidos, exceto a glicina, tem duas formas assimétricas ou enantiómeras, a forma $D$ e $L$, que se distinguem pelas suas propriedades óticas. A racemização é um processo gradual e espontâneo em que uma solução pura, de uma das formas enantiómeras, se transforma numa solução mista, com igual quantidade das formas D e L. De um ponto de vista fisiológico, as formas $L$ participam num processo construtivo e as formas $D$ num processo degenerativo, pelo que as formas L são "exclusivas" de um novo ser, e a racemização ou o crescimento contribui para o aumento das formas D. Este processo sofre a influência de fatores endógenos e exógenos, nomeadamente $\mathrm{pH}$ e temperatura. A dentina é um tecido mineralizado rico em colagénio e consequentemente em ácido aspártico que sofre um processo de racemização lento numa matriz insolúvel. A técnica de estudo da racemização do ácido aspártico é a que apresenta menor desvio padrão, cerca de 3 anos comparativamente com as técnicas anteriormente citadas em indivíduos adultos [48].

\section{V.4. REFERÊNCIAS}

[1] Cattaneo, C., Ritz-Yimme, S., Gabriel, P. e col. (2009). The difficult issue of age assessment on pedo-pornographic material. Forensic Sci Inter, 183(1-3): pp.e21-e24.

[2] Demirjian, A., Buschan, P.H., Tanquay, R. e col. (1985). Interrelationships among measures of somatic, skeletal, dental, and sexual maturity. Am J Orthodontics Dentofacial Orthopedics. 88(5), pp.433-438. 
[3] Miles, A.E.W. (1963). Dentition in the estimation of Age. J Dent Res, 42, pp. 255-263.

[4] Thomson, A.T. (1836). Lectures on medical jurisprudence now in course of delivery at London University: Lancet, pp. 281-286.

[5] Saunders, E. (1837). The teeth, a test of age, considered with reference to the factory children: adressed to the members of both houses of Parliament. London, UK: Renshaw.

[6] Schour, I., Massler, M. (1941). The development of the human dentition. J Am Dent Ass, 28, pp.1153-1160.

[7] Demirjian, A., Goldstein, H., Tanner, J.M. (1973). A new system of dental age assessment. Human Biology, 45, pp.211- 227.

[8] Cunha, E., Magalhães, F., Abade, A. (1999). How reliable are the skeleton indicators for subadult's age at death estimation? A test with the Coimbra identified skeletal collection. Am J Phy Antropol, 28, pp.112-113.

[9] Cunha, E., Martrille, L., Ramsthaler, R. e col. (2009). The problem of aging human remains and living individuals: a review. Forensic Sci Int, 193, pp.1-13.

[10] Garn, S.M., Lewis, A.M., Kerewsky, R.S. (1965). Genetic, Nutritional, and Maturational Correlates of Dental Development. J Dent Res, 44, pp.228-242.

[11] Garn, S.M., Lewis, A.M., Blizzard, R.M. (1965). Endocrine Factors in Dental Development. J Dent Res, 44, pp.243258.

[12] Hillson, S. (1996). Dental Anthropology. Cambridge University Press: Cambridge.

[13] Ubelaker, D.H. (2005). Skeletal Biology Research in Ecuador. Studies in Historical Anthropology, 2(2002), pp.45-58.

[14] AlQathani, S.J., Hector, M.P., Liversidge, H.M. (2010). Brief communication: The London Atlas of human tooth development and eruption. Am J Phys Anthropol, 142(3), pp.481-490.

[15] Senn, D.R., Weems, R.A. (2013). Manual of Forensic Odontology. (5 $5^{\mathrm{a} e d .}$ ), pp.218.

[16] Moorees, C.F.A., Fanning, E.A., Hunt, E.E. (1963). Age variation of formation stages for ten permanent teeth. J Dent Res, 42, pp.1490-1497.

[17] Anderson, D.L., Thompson, G.W., Popovich, F. (1976). Age of attainment of mineralization stages of the permanent dentition. J Forensic Sci, 21, pp. 191-200.
[18] Demirjian, A., Goldstein, H. (1976). New system for dental maturity based on seven and four teeth. Ann Hum Biol, 3(5), pp. 411-421.

[19] Willems, G., Olmen, V., Spiessens, B. e col. (2001). Dental age estimation in Belgian chidren: Demirjian's technique revisited. J Forensic Sci, 46, pp. 893-895.

[20] Leurs, I.H., Wattel, E., Aartman, I.H.A. (2005). Dental age in Dutch children. Eur J Orthodontics, 27, pp. 309-314

[21] Blenkin, M.R., Evans, W. (2010). Age estimation fron the teeth using a modified Demirjian system. J Forensic Sci, 55, pp. 1504-1508.

[22] Cameriere, R., Ferrante, L., Cingolani, M. (2006). Age estimation in children by measurement of open apices in teeth. Int J Legal Med, 120, pp.49-52.

[23] Galić, I., Vodanović, M., Cameriere, R. e col. (2011). Accuracy of Cameriere, Haavikko, and Willems radiographic methods on age estimation on Bosnian-Herzegovian children age groups 6-13. Int J Legal Med, 125: pp.315-321.

[24] Cameriere, R., DeAngelis, D., Ferrante, L. e col. (2007). Age estimation in children by measurements of open apices in teeth: a European formula. Int J Legal Med, 121: pp.449-53.

[25] Mincer, H.H., Harris, E.F., Berryman, H.E. (1993). The ABFO study of third molar development and its use as an age estimator of chronological age. J Forensic Sci, 3, pp.379-390

[26] Bolanos, M.V., Moussa, H., Manrique, M.C. e col. (2003). Radiographic evaluation of third molar deleopment in Spanish children and young people. Forensic Sci Int, 33(3), pp.212-219.

[27] Liversidge, H.M. (2008). Timing of human mandibular third molar formation. Ann Hum Biol, 35(4), pp.452-453

[28] Tomás, L.F. (2005). Padrões de erupção e calcificação dentárias numa amostra populacional portuguesa. Interesse médico-legal. Dissertação de Mestrado em Medicina Legal publicada. Faculdade de Medicina da Universidade de Coimbra.

[29] Nolla, C.M. (1960). The development of the permanent teeth. J Dent Children, 27, pp. 254-266.

[30] Julio, P. (2007). Estimativa da idade em indivíduos vivos não-adultos: aplicação do método de Demirjian a uma população portuguesa. Dissertação de Mestrado em Ciências Forenses publicada. Faculdade de Medicina. Universidade do Porto. 
[31] Cardoso, H.F., Heuzé, Y., Júlio, P. (2010). Secular changes in the timing of dental root maturation in Portuguse boys and girls. Am J Hum Biol, 22(6), pp.791-800.

[32] Liversidge, H.M., Molleson, T. (1999). Developing permanent tooth length as an estimate of age. J Forensic Sci, 44, pp.917-920.

[33] Cardoso, H.F. (2009). Accuracy of developing tooth length as an estimate of age in human skeletal remains: the permanent dentition. Am J Forensic Med Pathol, 30(2), pp.127-133.

[34] Cardoso, H.F. (2007). Accuracy of developing tooth length as an estimate of age in human skeletal remains: the deciduous dentition. Forensic Sci Int, 172(1), pp.17-22.

[35] Caldas, I.M., Júlio, P., Simões, R.J. e col. (2011). Chronological age estimation based on third molar deleopment in a Portuguese population. Int J Legal Med, 125(2), pp.235-243.

[36] Caldas, I.M., Carneiro, J.L., Teixeira, A. e col. (2012). Chronological course of third molar eruption in a Portuguese population. Int J Legal Med, 126(1), pp.107112.

[37] Kvaal, S., Kollveit, K.M., Thomsen, I.O. e col. (1995). Age estimation of adults from dental radiographs. Forensic Sci Int, 74, pp.175-185.

[38] Cate, A.R., Thompson, G.W., Dickinson, J.B. (1977). The estimation of age of skeletal remains from the colour of roots of teeth. Dent J, 43, pp.83-86.

[39] Lackovic, K.P., Wood, R.E. (2000). Tooth root colour as a measure of chronological age. J Forensic Odonthology, 18, pp.37-45.

[40] Gustafson, G. (1950). Age determination on teeth. J Am Dent Assoc, 41, pp.45-54.

[41] Molnar, S. (1971). Human tooth wear, tooth function, and cultural variability. Am J Phys Anthropol, 34, pp.175-189.

[42] Johanson, G. (1971). Age determinations from human teeth: A critical evaluation with special consideration of changes after fourteen year of age. Odontologisk Revy, 22, pp.1-126.

[43] Maples, W.R. (1978). An improved technique using dental histology for estimation of adult age. J Forensic Sci, 23(4), pp.764-770.

[44] Cameriere, R., Ferrante, L., Cingolani, M. (2004). Variations in Pulp/Tooth Area Ratio as an Indicator of Age: a Preliminary Study. J Forensic Sci, 49(2): pp.1-3.
[45] Cameriere, R., Cunha, E., Sassaroli, E. e col. (2009). Age estimation by pulp/tooth area ratio in canines: study of a Portuguese sample to test Cameriere's method. Forensic Sci Int, 193(1-3): 128, pp.e1-e6.

[46] Cameriere, R., Ferrante, L. (2011). Canine pulp ratios in estimating pensionable age in subjects with questionable documents of identification. Forensic Sci Int, 206(1-3), pp.132-135.

[47] Cameriere, R., Cunha, E., Wasterlain, S.N. (2013). Age estimation by pulp/tooth ratio in lateral and central incisors by peri-apical X-ray. J Forensic Legal Med, 20, pp.530-536.

[48] Kanchan-Talreja, P., Acharya, A., Naikmasur, V.G. (2012). An assessment of the versatility of Kvaal's method of adult dental age estiation in Indians. Arch Oral Biol, 57(3), pp. 277-284.

[49] Solheim, T. (1993). A new method for dental age estimation in adults. Forensic Sci Int, 59, pp.137-147.

[50] Bang, G., Ramm, E. (1970). Determination of age from root dentine transparency. Acta Odonto Scand, 28, pp.3-35.

[51] Soomer, H., Ranta, H., Lincoln, M. e col. (2003). Reliability and validity of eight dental age estimation methods for adults. J Forensic Sci, 48(1), pp.149-152.

[52] Lamendin, H., Baccino, E., Humbert, J.F. e col. (1992). A simple technique for age estimation in adult corpses: the two criteria method. J Forensic Sci, 37, pp.1373-1379.

[53] Baccino, E., Schmitt, A. (2006). Determination of adult age at death in Forensic Contexts. In Schmitt, A., Cunha, E., Pinheiro, J. (2006). Forensic Anthropology and Medicine Complementary Sciences from recovery to cause of death. Tottowa. Humana Press, pp.259-280.

[54] Martrille, L., Ubelaker, D., Cattaneo, C. (2007). Comparsion of four skeletal methods for the estimation of age at death on white and black adults. J Forensic Sci, 52(2), pp.302-307.

[55] Gocha,T.P., Scutkowski, H. (2013). Tooth cementum annulations for estimation of age-at-death in thermally altered remains. J Forensic Sci, 58, pp.S151-S155.

[56] Ohtani, S., Yamamoto, T. (2010). Age estimation by amino acid acemization inhuman teeth. J Forensic Sci, 55(6), pp.1630-1633 